\title{
Comparison of Two Analytical Techniques For Lead Determination in Soils and Mosses Samples
}

\author{
${ }^{1}$ Albert Maxhuni, ${ }^{2}$ Pranvera Lazo and ${ }^{1}$ Musaj Paqarizi \\ ${ }^{1}$ Department of Chemistry, Faculty of Natural Sciences, University of Prishtina, Kosovo \\ ${ }^{2}$ Department of Chemistry, Faculty of Natural Sciences, University of Tirana, Albania
}

Received 2012-03-07; Revised 2012-06-21; Accepted 2012-06-21

\begin{abstract}
The aim of this study was to compare the results of the lead levels obtained by two different techniques in the soil and mosses samples taken from the entire territory of the Republic of Kosovo. The atmospheric deposition of lead through the biomonitoring technique was done for the first time in Kosovo by using quartz tube flame Atomic Absorption Spectroscopy (AAS) and furnace AAS. The analytical results obtained by both techniques were very close to each other for the concentration of lead up to $0.15 \mathrm{mg} \mathrm{kg}^{-1}$. Mosses were used as bioindicators due to the purpose that they take the food from the rainfall and atmospheric dust. Two types of terrestrial mosses (Pseudosclerpodium purum and Hypnum cupressiforme) and the soil, collected in June-July 2011 at 25 sites evenly distributed over the whole region of Kosovo, were used in this study. The lead concentration varies from $\sim 11-416 \mathrm{mg} \mathrm{kg}^{-1}$ in the soil and from $\sim 3-50$ $\mathrm{mg} \mathrm{kg}{ }^{-1}$, DW in mosses, depending on the pollution zone. From the obtained results, we conclude that the lead levels are higher at the sampling positions near the polluted area of industry and heavy traffic.
\end{abstract}

Keywords: Atmospheric deposition, trace elements, lead, air pollution, soil pollution, quartz tube technique

\section{INTRODUCTION}

The method of utilizing mosses as bioindicators was applied more than three decades ago (Ruhling and Tyler 1973) and now is a widely accepted method for estimation of atmospheric depictions of metals (Ruhling and Steinnes 1998; Harmens et al., 2004). Mosses have only a rudimentary root system and take up elements from the atmosphere. This method has as advantage the simple sample collection and relative easiness of analysis compared to other techniques used for this purpose. The results from the survey of mosses analyzes allow examination of temporal and spatial distribution of different inorganic and organic pollutants and also the identification of the particular areas that are highly polluted from this metal due to the long-range transport and other local sources.

The technique using moss as bioindicators for assessing heavy metal distribution had been successfully applied by different groups (Ermakova et al., 2004; Barandovski et al., 2008).

$\mathrm{Pb}$ in soil represents a major environmental and human health concern due to their high toxicity, low biodegradability and cumulative tendency.
In the Republic of Kosovo so far there is no monitoring program that deals with the traces metals determination in the atmosphere. From the results of previous studies (Borgna et al., 2009) it was pointed out that some areas are contaminated with elevated levels of lead and other heavy metals in Kosovo. The primary goal is to have an overview regarding the distribution of heavy metals from atmospheric deposition from air and soil pollution. Aiming to achieve a low cost analysis, the levels of lead in the moss samples were determined by two different atomic absorption spectrophotometry techniques: A) quartz tube flame AAS; b) graphite furnace AAS; and the results were compared.

\section{MATERIALS AND METHODS}

\subsection{Study Area}

The Republic of Kosovo, located in the central part of Balkan, is a landlocked country with an area of 10,887 $\mathrm{km}^{2}$ with approximately $63 \%$ of the territory in mountainous regions. The country's population is around 2 million people. The major urban areas are Pristina, Mitrovica, Prizeren, Peja, Gjakova, Gjilan and Podujeva. 


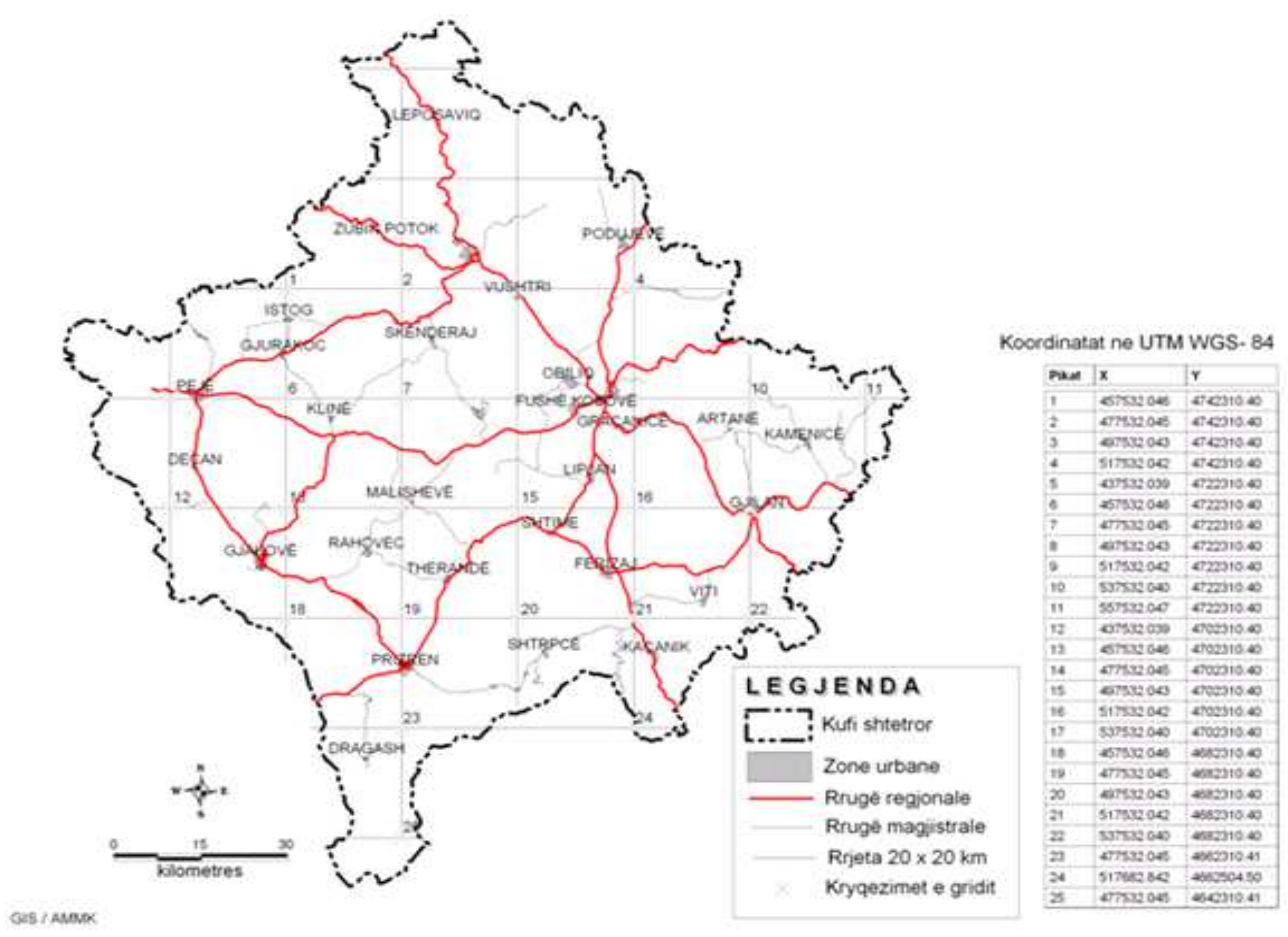

Fig. 1. Coordinates of sampling positions

\subsection{Sampling Sites}

Samples include soil and mosses species: Pseudosclerpodium purum and Hypnum cupressiforme, collected at 25 localities evenly distributed over the country during the period of June-July, 2011. The numbered sampling and coordinates of each sampling position are shown in Fig. 1.

The sampling is done according European mosses survey program ICP-Vegetation Sampling Manual, 2010 (Ruhling and Steinnes 1998). The mosses samples were collected in non-urban areas in a distance $300 \mathrm{~m}$ far from roads/and or highways, $100 \mathrm{~m}$ from local roads and 200 $\mathrm{m}$ from villages. Soil samples were collected near the same zone as mosses samples. Each sample was composed of five to ten sub-samples collected within an area of $50 \times 50 \mathrm{~m}^{2}$.

\subsection{Sample Pretreatment}

The mosses and soil samples were cleaned from extraneous plant material and air dried to constant weight $25-35^{\circ} \mathrm{C}$ for 3 days. The mosses samples were crushed by hand and are ready for analysis.

\subsection{Chemical Treatment of Moss Samples}

Wet digestion of a homogeneous moss sub-sample was applied. The simplest digestion of organic material samples is just nitric acid, which introduces a minimum of interferences in the subsequent analysis (Quevauviller et al., 2011). About $0.5 \mathrm{~g}$ moss sample was transferred to the half pressure Teflon tubes and $10 \mathrm{ml}$ nitric acid (9:1) was added. The closed tube was put at room temperature for $48 \mathrm{~h}$ and then was digested for $3 \mathrm{~h}$ at $80-90{ }^{\circ} \mathrm{C}$. The temperature was increased after at $200^{\circ} \mathrm{C}$ and was kept for an hour for further digestion. The tubes were opened and the acid was evaporated till very small volume. After cooling the mass was transferred to $25 \mathrm{ml}$ volumetric flasks and was filled till the mark with Osmoses treated water.

\subsection{Chemical Treatment of Soil Samples}

About $0.2 \mathrm{~g}$ of soil sample was digested with aqua regia (3HNO3: $1 \mathrm{HCl})$ in half pressure Teflon vessels in a hot plate for $2 \mathrm{~h}$ at $250^{\circ} \mathrm{C}$ and then was evaporated till wet salts. The digests were sent to volume with distilled water and stored at $4^{\circ} \mathrm{C}$ until analysis.

\subsection{The Determination of Lead in Moss and Soil Samples}

The concentration of lead was determined using nov AA400 Analytic Jena Spectrometer equipped with Furnace Atomizer and Auto Sampler; and Thermo M Series Atomic Spectrometer (flame system). Quartz tube is used to increase the sensitivity of lead in flame AAS measurements 
(Alvarado and Jaffe, 1998). The method using quartz tube is utilized in order to achieve higher sensitivity for lead determination (Matusiewiez and Kopras, 1995).

\subsection{Quality Control of the Analysis}

The quality control of soil samples was performed through the analysis of CRM sample IAEA 433. The results of the analysis are in good accordance with the declared value of $\mathrm{Pb}$.

The quality control of moss samples was performed through double determinations and use of blanks and background correction at $273.3 \mathrm{~nm}$ and by comparing the 1; ead content of a moss sample (Hypnum cupressiforme species, collected in a clean rural area in Albania, Llogora, N: $40^{\circ} 12$ ' 31.1"; E: $19^{\circ} 35^{\prime}$ 06.7”) and analyzed by two different techniques: AAS and ICPAES. The results of the ICP method provided by the Institute of Chemistry, Faculty of Science, Ss. Cyril and Methodius University, are in good agreement with our results (AAS). The certified M2 and M3 moss sample was used for quality control of the analysis in ICP-AES analysis. The results of the analysis are in good accordance $\left(\mathrm{Pb}_{\mathrm{AAS} / \mathrm{ETA}}=2.93 \mathrm{mg} \mathrm{kg}^{-1}\right.$, DW; $\mathrm{Pb}_{\text {ICP-AES }}=2$. $98 \mathrm{mg} \mathrm{kg}^{-1}$, DW).

\section{RESULTS}

\subsection{Comparison of Furnace and Quartz Tube Flame AAS Technique in Determination of Lead}

24 soil samples and 25 moss samples collected in the same points as soil samples, were analyzed via graphite furnace AAS and quartz tube flame AAS. Linear regression analysis is used to compare the data set obtained by both techniques during the analysis of soil and moss samples (Fig. 2 and 3).

As shown from the linear regression graphs of soil samples (Fig. 2) and mosses samples (Fig. 3), for both techniques gave the similar and comparable results. In both cases the values of the linear coefficients $\left(\mathrm{R}^{2}\right)$ are higher than 0.88 , indicating good linearity of the data obtained by both techniques. The linear coefficient obtained from the data of soil samples $\left(\mathrm{R}^{2}=0.9942\right)$ is better than of the data of moss samples.

In both cases the values of the linear coefficients $\left(\mathrm{R}^{2}\right)$ are higher than 0.88 , indicating good linearity of the data obtained by both techniques. The linear coefficient obtained from the data of soil samples $\left(\mathrm{R}^{2}=\right.$ 0.9942) is better than of the data of moss samples. Since the content of lead in moss samples is near to the detection limit of the method, the result obtained is satisfied.

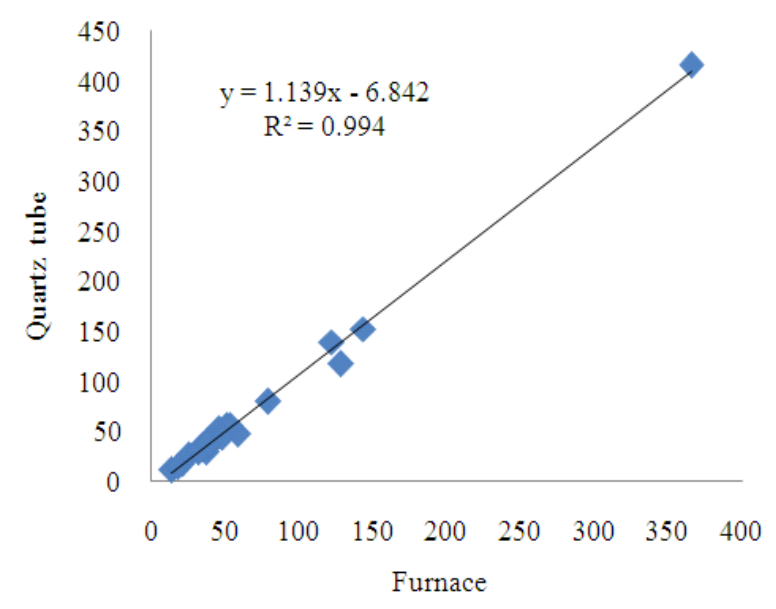

Fig. 2. Linear Regression between the results of $\mathrm{Pb}$ obtained via quartz tube flame AAS and furnace AAS technique for soil samples

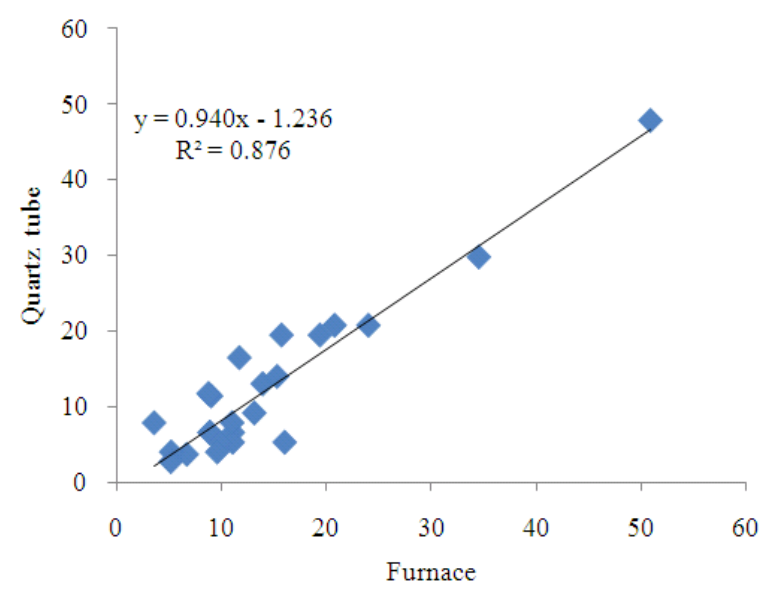

Fig. 3. Linear Regression between the results of $\mathrm{Pb}$ obtained via quartz tube flame AAS and furnace AAS technique for moss samples

Table 1. t-TEST: Paired two samples for means

\begin{tabular}{|c|c|c|c|c|}
\hline \multirow{4}{*}{$\begin{array}{l}\text { Statistical } \\
\text { Parameter }\end{array}$} & \multirow{4}{*}{$\begin{array}{l}\text { Soil } \\
\mathrm{Pb} \\
\text { Furnace }\end{array}$} & \multirow{4}{*}{$\begin{array}{l}\text { Samples } \\
\text { Moss } \\
\mathrm{Pb} \\
\text { Q. Tube }\end{array}$} & \multicolumn{2}{|l|}{ Samples } \\
\hline & & & $\mathrm{Pb}$ & $\mathrm{Pb}$ \\
\hline & & & Furnace & Q. Tube \\
\hline & & & & \\
\hline Mean & 64.00 & 67 & 14.20 & 12.5 \\
\hline Observations & 24.00 & 24 & 25.00 & 25.0 \\
\hline Pearson Correlation & 0.998 & & 0.952 & \\
\hline \multicolumn{5}{|l|}{ Hypothesized Mean } \\
\hline Difference & 0.000 & & 0.000 & \\
\hline $\mathrm{P}(\mathrm{T}<=\mathrm{t})$ one-tail & 0.153 & & 0.007 & \\
\hline t Critical one-tail & 1.714 & & 1.711 & \\
\hline $\mathrm{P}(\mathrm{T}<=\mathrm{t})$ two-tail & 0.307 & & 0.013 & \\
\hline t Critical two-tail & 2.069 & & 2.064 & \\
\hline
\end{tabular}




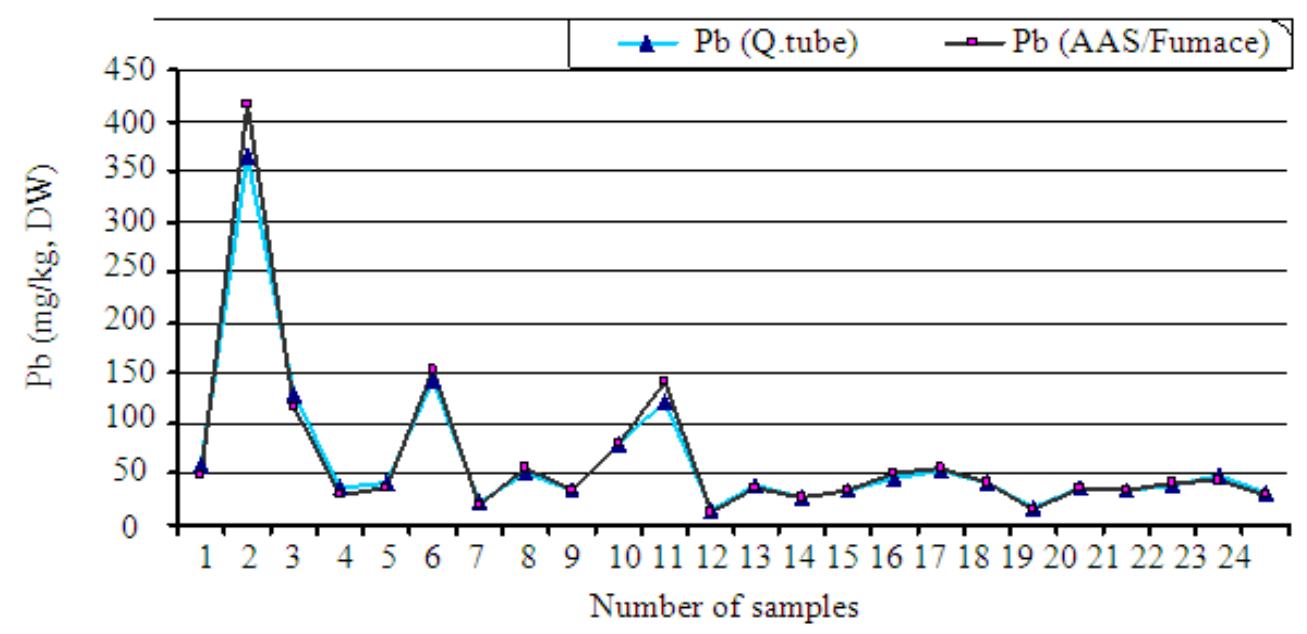

Fig. 4. Lead level in the soil samples determined by furnace and quartz tube technique

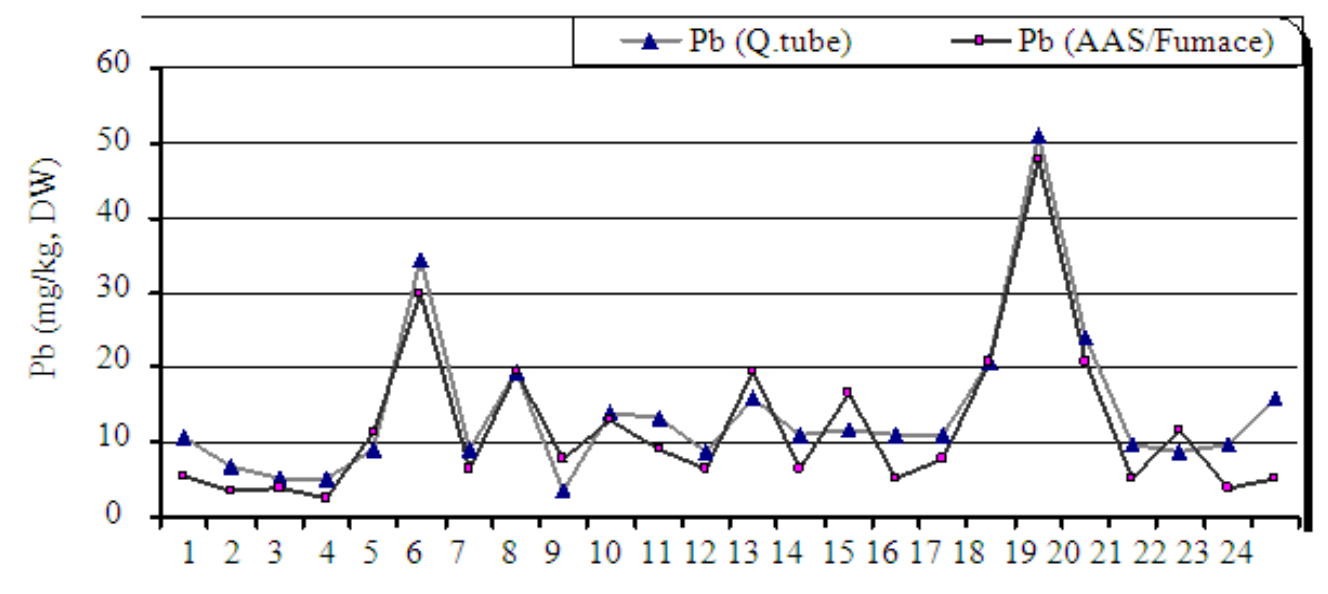

Number of samples

Fig. 5. Lead level in mosses samples determined by furnace and quartz tube technique

Table 2. The range of variation of lead in mosses samples of Kosovo and some other countries (Spiric et al., 2009; Lazo et al., 2012), mg/kg, dry weight

\begin{tabular}{ll}
\hline Country & $\mathrm{Pb}$ \\
\hline Kosovo & $3-50$ \\
Albania** & $1.34-5.38$ \\
Norway* & $0.64-6.12$ \\
Romania* & $6.45-31.5$ \\
Croatia* & $0.06-82.4$ \\
Macedonia* & $1.5-37.2$ \\
\hline
\end{tabular}

\section{DISCUSSION}

The slopes obtained from linear regression of the data sets $(\mathrm{a}=0.9406$ for moss samples and 1.1396 for soil samples) are close to 1, indicating comparable results for both techniques. The linear regression equation obtained from the data of moss samples $(y=$ $0.9406 x-1.2365)$, with $a=9406<1$ and a negative value of $b(b=-1.24)$ show a small negative systematic error on the data obtained by quartz tube flame AAS. For a better comparison and interpretation of the results, the statistical t test was calculated. The results are shown in Table 1.

As is shown from the Table 2, the Pearson productmoment correlation coefficient is very close to 1 , proving the strength of linear dependence between two variables for both cases (soil and moss samples). The 
values of t-tests (one tail and two-tail t-tests) of both cases are smaller than the corresponding values of critical t-test, indicating no significant differences exist between the results obtained during the determination of lead with furnace AAS and a quartz tube flame AAS in soil and moss samples. The analytical results for soil and moss samples are presented in the graphs given in Fig. 4 and 5.

The levels of lead in soil samples (Fig. 4) varied from $\sim 11-416 \mathrm{mg} \mathrm{kg}^{-1}$, dry weight. This variance is due to the pollution in some regions caused mainly from industry (KS2, KS3, KS6 and KS11).

The lead levels in mosses samples (Fig. 5) varied from $\sim 3-50 \mathrm{mg} \mathrm{kg}^{-1}$, dry weight. This variance is due to the pollution in last recent years from air; here correlation with the soil samples is complex due to the fact that the deposition is dependent from air currents and atmospheric precipitation. The highest lead levels were found for samples KS6, KS8 and KS19.

As shown from the data given in Table 2, the range of variation of lead in moss samples collected in Kosovo, is comparable with the data published in Croatia, Macedonia and Romania, but higher than the data published in Albania and Norway.

\section{CONCLUSION}

As show above on the correlation graph between two techniques (using furnace/quartz tube), both of them gave results with similar comparable values and have a high sensitivity for lead determination by quartz tube flame AAS.

From the obtained results of this study, we see that the concentration of lead has reached high levels in soil samples in the Mestrovic's region (Fig. 4, samples KS2 and $\mathrm{KS} 3$ ), which is caused as a result of industrial pollution from the Trepça mining and metallurgical complex (smelters, flotation, battery production). Other studies in this region show also high levels of lead (Borgna et al., 2009; OBSH-MMPH-IKSHP). In comparison with soil, in the mosses samples the lead levels in this region are low due to the fact that the mosses represent the two or three last years of lead levels, at a time at which Trepça has stopped the industrial activities. The concentration of lead is high in soil and mosses in the sample (KS6 Fig. 5) which is related with the Ferro-Nickel factory which operates in its full capacity of production, in the sample KS11 the elevated level of lead is due to the pollution from mining and flotation of lead and zinc.

\section{REFERENCES}

Alvarado, J. and Jaffe R., 1998. Tube in flame atomization: A way of enhancing detection limits in flame atomic absorption spectrometry. J. Anal. At. Spectrm., 13: 37-40. DOI: 10.1039/A704688J

Borgna, L., L.A. Di Lella, F. Nannoni, A. Pisani and E. Pizzetti et al., 2009. The high contents of lead in soils of northern Kosovo. J. Geochemical Exploration, 101: 137-146. DOI: 10.1016/j.gexplo.2008.05.001

Barandovski, L., M. Cekova, M.V. Frontasyeva, S.S. Pavlov and T. Stafilov et al., 2008. Atmospheric deposition of trace element pollutants in Macedonia studied by the moss biomonitoring technique. Environ. Monit Asse., 138: 107-118. DOI: 10.1007/s 10661-007-9747-6

Quevauviller, P., P. Roose and G. Verreet, 2011. Chemical Marine Monitoring: Policy Framework and Analytical Trends. 1st Edn., John Willey and Sons, Chichester, ISBN-10: 1119990831, pp: 472.

Ermakova, E.V., M.V. Frontasyeva, S.S. Pavlov, E.A. Povtoreyko and E. Steinnes et al., 2004. Air pollution studies in central Russia (Tver and Yaroslavl Regions) using the moss biomonitoring technique and neutron activation analysis. J. Atmospheric Chem., 49: 549-561. DOI: $10.1007 / \mathrm{s} 10874-004-1265-0$

Harmens, H., A. Buse, P. Buker, D. Norris and G. Mills et al., 2004. Heavy metal concentrations in European mosses: 2000/2001 survey. J. Atmospheric Chem., 49: 425-436. DOI: 10.1007/s 10874-004-1257-0

Lazo, P., M. Vasjari, T. Stafillov, M.V. Frontasyeva and M. Terpo et al., 2012. Moss biomonitoring in Albania: Present and future. Proceedings of the 25 th ICP Vegetation Task Force Meeting, Jan. 31-Feb. 02, Bres, Italy.

Matusiewiez, H. and M. Kopras, 1995. Paper Presented at XXIX Colloquium Spectroscopicum International. 1st Edn., Leipzig, Germany, pp: 297.

Ruhling, A. and G. Tyler, 1973. Heavy metal deposition in Scandinavia. Water, Air Soil Pollu., 2: 445-455. DOI: $10.1007 /$ BF00585089

Ruhling, A. and E. Steinnes, 1998. Atmospheric heavy metal deposition in Europe 1995-1996. Nordic Council of Ministers, Copenhagen, ISBN-10: 9289302542 pp: 66.

Spiric, Z., M. Frontasyeva, E. Steinnes and T. Stafilov, 2009. Multi-element atmospheric deposition study in Croatia. Int. J. Environ. Analytical Chem. DOI: 10.1080/03067319.2011.561336 